\title{
JUAN DE TOLEDO Y EL PINTOR CATALÁN JERONI FRANCOLÍ
}

Durante el largo pontificado del papa Barberni Urbano VIII, Roma se convirtió definitivamente en un punto de confluencia de las diversas naciones de la Europa moderna. Las embajadas extranjeras en la ciudad papal actuaban de intermediarias entre el pontífice y los soberanos que procuraban mantener el favor del papa intentando influir en la curia de cardenales, con la finalidad de lograr la deseada aprobación a su política militar en tierras italianas. En este sentido, la tarea principal de la embajada española residía en bloquear los avances de la diplomacia francesa contrarios a los designios de Felipe IV, y negociar con el papado las ventajas de una ulterior fidelidad a la corona de España. La embajada era un núcleo social de gran distinción e importancia, en cuanto permitía al aristócrata designado lucirse en una sociedad integrada por potentados provenientes de las más lustrosas familias de Europa ${ }^{1}$. A este lucimiento contribuyeron gran número de artistas españoles residentes en Roma, ávidos de servir a una aristocracia favorecida desde España por el gobierno de Felipe IV, aunque frecuentemente era el propio embajador quien debía costear con sus propios recursos el tren de vida exigido; con el consiguiente dispendio y ruina sólo compensado por la expectativa de ejercer un mejor y más lucrativo cargo.

Otro gran foco de atracción, al margen de la embajada, fue sin duda la naturaleza de la propia administración vaticana y la gran cantidad de procesos y asuntos que se decidían en los muchos foros y tribunales eclesiásticos. Los desplazados a Roma para la gestión en tribunales, secretariados, embajadas y negocios públicos o particulares fueron incontables; a todos ellos una vez llegados a la ciudad se les reconocía por el barrio en donde se alojaban, y por los lugares y personas a las que acudían. En medio de este tráfico incesante de personas y despachos se contaban también los artistas deseosos de contemplar en origen las más excelentes obras de arte repartidas por toda la ciudad, ya mitificadas por una literatura artística cada vez mejor consolidada ${ }^{2}$, obras y estudios que más tarde incorporarían con mayor o menor acierto a su propio repertorio estético. La formación que para un artista podía suponer el viaje a Roma era ya a mediados del siglo XVII, un hecho determinante que muy bien podía facilitar la posibilidad de contactar con un buen patrono aristócrata o eclesiástico conciudadano, que pudiera asegurar un fructífero mecenazgo, incluso en el propio país de origen dada la temporalidad que solían tener los negocios tratados en Roma.

Estas dos posibilidades expuestas (servicio en la embajada española y mecenazgo fruto de algún negociado eclesiástico) parecen haber sido las circunstancias más probables que explicarían la presencia y el enfrentamiento en las calles de Roma de Jeroni Francolí, un desconocido pintor catalán residente en Roma el año 1642, con el pintor y militar castellano Juan de Toledo. La noticia procede de la mención de un anónimo dietarista romano, que entre otros muchos incidentes de las calles de la ciudad anotó la escaramuza sostenida entre ambos pintores ${ }^{3}$. Identificamos al pintor Giovanni di Toledo, citado en el documento italiano, con

1 Sobre el papel del embajador en la España moderna Vid. Juan de Vera y Figueroa: «El Embajador», Sevilla 1620; y J. M. Pou Martí: «Archivo de la embajada de España cerca de la Santa Sede; índice analítico de los códices de la biblioteca contigua al archivo», Roma 1925.

2 En este sentido vid. el diálogo primero de V. Carducho: «Diálogos de la pintura»; edición de Calvo Serraller, Madrid ed. Turner 1979.

3 Biblioteca de la Universidad de Barcelona, Ms. 463: Anónimo: «Gabinetto di curiositá nel Pontificato d'Urbano ottavo; tomo primo. Relazione di Roma o sia memoria curiosa de casi e contese gravi con cardinale, ambasciatore e Principi; e de le litti seguiti in Roma al tempo d'Urbano ottavo con una piena notitia de'trattati, temperamenti, gratie e castighi ett». Fols. 66 y 67. El manuscrito relata cronológicamente diversos sucesos romanos fechados a partir 
el soldado pintor de Lorca ateniéndonos al carácter militar de éste y a su paso por Italia, circunstancia que concuerda además con la fecha propuesta, teniendo sin embargo presente el hecho de que se trata de un personaje aún poco documentado. Aun así la personalidad de este artista nos es más conocida que la de su oponente, gracias a la mención que hacen de él los antiguos diccionarios biográficos de artistas españoles editados desde la época de Palomino; la cual cosa nos puede sugerir que en su momento debió haber adquirido un cierto prestigio como pintor cortesano, cuyas obras anteriores y posteriores a su permanencia en tierras italianas que se le han atribuido, configuran todavía un incierto catálogo falto de mayor concreción documental ${ }^{4}$.

Sin duda su faceta de militar debió corresponder a un carácter violento, hecho que en el momento del enfrentamiento con Francolí se debería ver más acentuado en tanto que la fecha de 1642 coincide con el período de la revuelta catalana contra el gobierno de Felipe IV y Olivares. En este sentido es importante destacar el hecho que Juan de Toledo servía en Roma al marqués de los Vélez, que en aquel momento ostentaba el cargo de embajador ${ }^{5}$.

Pedro Fajardo de Zúniga y Requesens, marqués de los Vélez, destacó por su participación militar en la guerra de Cataluña, dirigiendo las tropas castellanas en una primera campaña poco afortunada contra las tropas franco-catalanas ${ }^{6}$. La acción militar más destacada de este aristócrata fue precisamente su derrota en la batalla de Montjuïc, cuando pretendía rendir la ciudad de Barcelona. Episodio que muy posiblemente fuera aludido por Juan de Toledo en alguna de las pinturas de batallas que se le atribuyen; aunque es bastante improbable que dicho pintor hubiera participado directamente en ella. La irregular carrera militar del marqués de los Vélez finalizó con su propia muerte en Sicilia, siendo virrey, después de la revuelta de 1647.

Juan de Toledo habría estado en Italia al menos en dos ocasiones sirviendo como arcabucero en el estado de Milán donde permaneció dos años y medio; partiendo de nuevo

de 1635, siendo embajador el marqués de Castel Rodrigo. Básicamente se da noticia de la delincuencia callejera, enfrentamientos entre franceses y españoles, meretrices, robos y asesinatos. Destacamos también diversas menciones a otros artistas italianos envueltos en diversos escándalos; (Fol. 26v) encarcelamiento a 1 de enero de 1637 del pintor romano Giovanni Battista Greppi, por enfrentamientos con el personal del cardenal de Saboya. (Fol. 38v) secuestro a 7 de noviembre de 1637 de Plautilba Azzolini, esposa del pintor Francesco Borbone.

A estas noticias referidas a pintores de la ciudad de Roma ofrecidas por el dietarista, cabría añadir la breve alusión al cuadro de Rafael La virgen del Pez (Museo del Prado), que desde la primera mitad dels siglo XVI colgaba en el altar de San Domenico de Nápoles, y que el duque de Medina de las Torres, entonces virrey, consiguió de manera poco ortodoxa llevar a España, donde más tarde formaría parte de las colecciones de Felipe IV (Vid. M. Mena Marqués: «Presencia histórica de obras de Rafael en España» Rafael en España, Madrid 1985 pp. 1128). Este hecho se sumaba a los argumentos aducidos contra el Prior de los dominicanos en Nápoles cuando fue acusado de desafección por el papa, cuestionando su proceder en éste y otros asuntos. El dietarista anónimo mencionó el hecho al enumerar el tercer cargo presentado en su contra:

(Fol. 90v, fechado en 27 de abril de 1642) La $3^{\circ}$ che egli habbia donato un quadro belis ${ }^{\circ}$. di mano di Rafaele d'Urbino, al Sige. Viceré di Napoli che stava nella chiesa di detta città; al ch'egli risponde che quel quadro non era della chiesa, mà di un testatore particolare che lo pose in $\mathrm{d}^{\mathrm{a}}$ chiesa con proibitione di non rimuoverlo sotto pena di pagare $3 \mathrm{~m}$. scudi alli ministri della Nuntiata di $\mathrm{d}^{\mathrm{a}}$ città, con li quali il do Viceré si era aggiustato senza intervento suo.

${ }^{4}$ Acerca de Juan de Toledo vid. J. L. Morales Marín: «El capitán pintor Juan de Toledo». Goya nº 134, Madrid 1976. D. Angulo Íñiguez/A. Pérez Sánchez: «La escuela madrileña del segundo tercio del siglo XVII». Instituto Diego Velázquez, C.S.I.C., Madrid 1983; pp. 336-355, láms. 343-352. Ma․ Va․ Caballero Gómez: «Juan de Toledo, un pintor en la España de los Austrias», Madrid, 1985. J. C. Agüera Ros: «Un ciclo pictórico del 600 murciano», Murcia, 1982.

5 En el mismo manuscrito, otra versión de los hechos más reducida en el Fol. 88v, donde se afirma explícitamente en el texto que el pintor castellano estaba al servicio del marqués de los Vélez.

6 Sobre las campañas militares del marqués de los Vélez en Cataluña Vid. J. Sanabre: «La acción de Francia en Cataluña (1640-1659)». Barcelona 1956. 
hacia 1638 cuando se alistó por segunda vez en el ejército alcanzando en este período el grado de capitán; regresando finalmente a Murcia en el año $1643{ }^{7}$. Con toda certeza fue su servicio en el ejército el medio que debió facilitar su contacto en la embajada española de Roma, así mismo la posibilidad de servir directamente al embajador en su doble cualidad de pintor y militar. En este sentido es significativo el dato aportado por el dietarista cuando afirma que el pintor residía en su palacio.

Ante esta más que probable protección del marqués de los Vélez cabría destacar la posición del pintor Jeroni Francolí; el hecho de que momentos antes de batirse con Juan de Toledo saliera de la casa de un eclesiástico catalán no identificado (el abate Massoni, tal como lo nombra el dietarista) daría pie a pensar en un posible protector eclesiástico de este artista. En todo caso la escaramuza se complicó bastante para éste y para otros catalanes residentes en Roma. En la persecución de Juan de Toledo, que oportunamente escapaba hacia el palacio del embajador, Francolí topó con dos aristócratas franceses que momentos antes se habían batido con unos españoles, uno de ellos el conde Giovanni Claudio Lorenese estaba herido. Francolí fue preso y conducido al palacio del embajador; entre tanto una guardia de soldados castellanos acompañaron a los aristócratas hacia su alojamiento, por el camino encontraron un grupo de catalanes con quienes intercambiaron disparos de arcabuz. Se iniciaría una persecución que acabaria con el saqueo de una vivienda y la huida por los tejados de catalanes e italianos. Finalmente, al no poder ser probada la culpabilidad del pintor catalán en todo aquel asunto, Francolí fue puesto en libertad.

Estos incidentes entre castellanos y catalanes en la ciudad de Roma debieron causar en más de una ocasión la preocupación de las autoridades, que debían soportar ver en sus propias calles una prolongación de la revuelta catalana, que en estos momentos se venía a sumar a las continuas disputas callejeras entre franceses y españoles, mostrando el desequilibrio que el enfrentamiento armado en tierras catalanas causaba en una Roma presidida por un papa filofrancés, y por un partido español dispuesto más que nunca a forzar su propia diplomacia ${ }^{8}$. Posiblemente por esta razón intervino directamente uno de los Barberini (el dietarista no especifica cual de ellos) que reclamó al marqués de los Vélez la libertad inmediata de Francolí en caso que su culpabilidad no pudiera ser demostrada.

SANTI TORRAS TILLÓ

DOCUMENTO: Biblioteca Universidad de Barcelona, Ms.463. Fols. 66-67 (8 de junio 1642) ${ }^{9}$.

Domenica sera otto di giugno verso l'hora tre di notte, essendo uscito di casa dell' Abate Massoni, catalano che habbitava poco lontano della piazza della Trinità, Girolamo Francolini, pittore, e Giacomo Gasio, amico del $d^{o}$ Filippo ${ }^{10}$; andarono verso la strada della Vita dove incontrarono Giovanni di Toledo, che habitava nel palazzo del Sige. Ambase. di Spagna parime. pittore, che haveva seco una donna, venne a parole con li sudeti sotto pretesto che lo burlassero dicendo questo ai catalani che fossero imbriachi, et ogni uno sequitó la sua strada; cio è Giovanni verso d $d^{a}$ piazza e gli altri verso la strada de'Condotti. E riuscendo tutti nella $d^{\underline{a}}$ piazza si rincon-

\footnotetext{
7 Consta también la noticia, quizas dudosa, de su trabajo en casa de Orrente en el año 1641 (D. Angulo Íniguez/A. Pérez Sánchez: Op. cit., p. 342; J. L. Morales Marín: Op. cit., p. 82).

8 De hecho el mismo dietarista incluye entre sus relaciones coetáneas, la narración de otros diversos enfrentamientos entre castellanos y catalanes dentro de la ciudad:

(Fol. 93v, 1642): «Hieri un catalano insolente per la strada publica, vicino al quartiere del Sige. Ambase. di Francia, insultó due castigliani e n'ebbe á nascere un grandiss ${ }^{o}$ rumore se non veniva ben presto riparato con la carceracione di questi».

9 Proponemos la fecha de 1642 en este caso como la más certera, teniendo en cuenta el notable desorden cronológico con que el dietarista expone las anotaciones de los años 1641 a 1643.

${ }_{10}$ Se trata de un personaje anteriormente mencionado en el texto.
} 
trarono di nuovo alla fontana, e subbito d ${ }^{o}$ Giovanni si cocció de la coccia una pistola e d ${ }^{o}$ Girolamo e compagni diedero mano alla spada; e Giovanni di Toledo sparó d $d^{a}$ pistola e restó ferito nel viso, e Girolamo restó ferito in una spalla. E postisi in fuga li spagnuoli sudi. li catalani li seguitarono quasi al palazzo del Sige. Ambase. ecceto che Girolamo pittore che solo voltó per la strada de'Borgognoni; e ritornato nella strada del Babuino sentí un francese lamentarsi che era ferito, et andando a quella volta fu fermato dal conde Gio. Claudio Lorenese e dal baron Franc ${ }^{o}$ Recourt, fiamengo, e presolo in mezzo minacciarono di volerlo ammazzare onde li chiese la vita in visceribus Christi con conseguarli la spada, fu da medmi. condotto al palazzo del Sige. Ambase. di Spagna anco legato fu tenuto tutta la notte.

La mattina saputosi ció dell'Emo Barbarino fecie farne dogliante col Sige. Ambase., di tal retentione che si era colpevole si consegnasse alla giustitia che si sarebbe castigato. Onde la sera susseguente fu lasciato in sua libertà. Il conte Gio. Claudio Lorenese era quello che si doleva d'essere ferito, et il successo passó in questo modo: Era questo, come si e $d^{o}$, in compagnia del baron Franc ${ }^{o}$ Recourt, fiamengo, che stava parlando di strada con una donna che era chiamata la Greca Curiale alla strada de'Greci, dove arrivarono dui spagnoli che venivano del Popolo, e non si sà chi fossero con fermarsi avanti la porta de $d^{a}$ Greca per sentire i raggionamenti del $d^{o}$ barone e conte, si voltarono contro di quelli domandandogli che cosa volevano, e rispondendo gl'altri dissero il med ${ }^{o}$ dalche dall'una e dall'altra parte si missero mano alle spade. Ne restó ferito $d^{o}$ conde, si diedero poi alla fuga, e a questo rumore sopragiunse il pittore del quale si e parlato di sopra.

Dopo seguiti i sudetti due fatti, uscirono di casa del Sige. Ambasciatore di Spagna molti armati di terzaroli in compagnia delli detti conte e barone, dicendo d'accompagnare a casa il ferito, e che incontratisi in alcuni catalani, che non li conobbero, da questi gli furono sparate dell'archibuggiate; ma incalsati dalli castigliani fugissero in una casa dove poi gl'altri entrassero con forzare la porta e non vi provassero nessuno, ma come non costa che i sudetti cattalani sparassero le dette archibugiate, cosí per il contrario apparisce che nella strada della Serena dove e detta casa, fu sentito un rumore di spade e genti dire Catalani ribelli ${ }^{11}$, che alla voce si conosceva esser spagnoli. E si videro da otto o dieci persone, parte armati e parte no, che andavano verso la piazza della Trinità, e che di li a poco ritornavano piú di trenta persone armate che, chi con terzaroli arrivati alla detta casa, spararono alcune archibugiate in strada. Et in questo mentre si sentí a bussare la porta della casa di Tomaso, cocchiero che habbitava sotto don Pietro Capponi, aperta questa a forza de calci entrarono in sala spararono varie archibugiate e restó malamente ferito il servitore di detto don Pietro, essendo il medemo ed'altri servitori costretti per salvarsi fugirsene per li tetti e finestre nelle case vicine; et i catalani si dolsero malamente, che oltre l'offesa ricevuta si trovarono mancarli molte robbe in casa. Fu di poi carcerato il pittore catalano, che como si disse era stato condotto in casa del Sige. Ambase., ma esaminato non si trovó colpevole auri offeso fu rilasciato, e gl'altri delinquenti non si poterono havere.

11 Clara alusión a la guerra que en aquellos momentos mantenían las tropas castellanas en Cataluña, y a la consideración de rebeldes a los catalanes residentes en Roma protagonistas de esta escaramuza. 